\title{
Performance evaluation of tomato crop under shadenet house and open field conditions in the Shahdol district
}

Deepak Chouhan, Mrigendra Singh, P.N. Tripathi and Alpana Sharma

Received : 05.01.2020; Revised : 05.02.2020; Accepted : 20.02.2020

See end of the Paper for authors' affiliation

Correspondence to :

Deepak Chouhan Krishi Vigyan Kendra (JNKVV), Shahdol (M.P.) India

Email: deepakchouhan22@ gmail.com
- ABSTRACT : The performance of tomato crop cultivation in open field and under shadenet house condition was evaluated at farmers field in Shahdol district. Under shadenet house condition green colour shade net having 50 per cent shade factor was used in the study. Similar crop along with similar cultural practices in the open field and shade net cultivation was selected for performance evaluation. Drip irrigation facility with similar frequency of irrigation was done on both fields. The study revealed that under shade net condition performance of tomato the crop yield, plant height, harvest duration and number of harvest increased by 56.92 per cent, 53.37 per cent, 38.86 per cent and 59.38 per cent, respectively over open field cultivation.

- KEY WORDS : Shadenet, Tomato, Yield, Plant characteristics, Plant height

- HOW TO CITE THIS PAPER : Chouhan, Deepak, Singh, Mrigendra, Tripathi, P.N. and Sharma, Alpana (2020). Performance evaluation of tomato crop under shadenet house and open field conditions in the Shahdol district. Internat. J. Agric. Engg., 13(1) : 48-51, DOI: 10.15740/HAS/ IJAE/13.1/48-51. Copyright@ @2020: Hind Agri-Horticultural Society. 